\title{
Television Viewing Does Not Have to Be Sedentary: Motivation to Participate in a TV Exercise Program
}

\author{
Jessie J. M. Meis, ${ }^{1,2}$ Stef P. J. Kremers, ${ }^{1,2}$ and Martine P. A. Bouman ${ }^{3}$ \\ ${ }^{1}$ Department of Health Promotion, Faculty of Health, Medicine and Life Sciences, Maastricht University, P.O. Box 616, \\ 6200 MD Maastricht, The Netherlands \\ ${ }^{2}$ Nutrition and Toxicology Research Institute Maastricht (NUTRIM), Maastricht University, P.O. Box 616, \\ 6200 MD Maastricht, The Netherlands \\ ${ }^{3}$ Center for Media \& Health, Peperstraat 35, 2801 RD Gouda, The Netherlands
}

Correspondence should be addressed to Jessie J. M. Meis, j.meis@maastrichtuniversity.nl

Received 30 May 2011; Revised 1 September 2011; Accepted 19 September 2011

Academic Editor: Dale Bond

Copyright (C) 2012 Jessie J. M. Meis et al. This is an open access article distributed under the Creative Commons Attribution License, which permits unrestricted use, distribution, and reproduction in any medium, provided the original work is properly cited.

\begin{abstract}
The present study explored which underlying motivations induced people to participate in a television exercise program called "The Netherlands on the Move!-television" (NOM-tv). A cross-sectional study was carried out among 1,349 viewers of NOMtv. The respondents completed the intrinsic motivation inventory (IMI), assessing their levels of intrinsic motivation towards participating in the NOM-tv exercises. The results showed that higher levels of intrinsic motivation (i.e. enjoying the NOM-tv exercises, feeling competent to perform this activity, and willingness to put effort into the exercises) were the most important predictive factors of more frequent participation in the NOM-tv exercises. Future screen-based interventions to reduce sedentary behavior should aim especially at encouraging people's intrinsic orientations towards physical activity in an autonomy-supportive way.
\end{abstract}

\section{Introduction}

Sedentary behavior has been found to be a predictor of weight gain [1], type 2 diabetes [2], cardiometabolic risk [3], specific cancers [4], cardiovascular diseases [5], and all-cause mortality and cardiovascular mortality [6-8]. Despite the evidence, sedentary lifestyles are increasing in most Western countries [9]. For older adults, increased physical activity is particularly important to reduce the risk of chronic illnesses and to maintain mobility, prevent falls, and improve healthrelated quality of life [10-12].

In 1995, the Dutch government decided to launch a national campaign called "The Netherlands on the Move" [13]. One part of this campaign was the introduction of a national daily television program in 2000 , called "The Netherlands on the Move!-television" (NOM-tv). Various national health organizations (such as the Dutch Heart Foundation, Netherlands Institute for Sport and Physical Activity, Netherlands Brain Foundation, and Dutch Cancer
Society) joined forces and initiated and coproduced this television program. NOM-tv was designed for adults (mainly targeting people aged 55 and over), to offer them an easily accessible, low-intensity, exercise facility: morning exercises being performed at home in front of the television. Whereas television viewing is typically considered to be a sedentary behavior, participation in NOM-tv can in fact be a first step towards a reduction of daily sitting time. NOM-tv shows that television viewing does not always have to be sedentary and this program may be regarded as an innovative way for health promotion interventions to make use of the popularity of screen viewing to reduce sedentary behavior.

NOM-tv is broadcast via the Dutch nation-wide publicservice broadcasting system. Over the years, NOM-tv has been continuously optimized by frequent process evaluations (formative research) among program viewers. NOM-tv is a popular television program, with approximately 137,000 viewers a day [14]. The program is broadcast on weekdays at $6.45 \mathrm{a} . \mathrm{m}$. and $9.10 \mathrm{a} . \mathrm{m}$. and with a replay on Saturdays and 
Sundays at $8.45 \mathrm{a} . \mathrm{m}$. The program lasts 15 minutes and starts with a general health education message. This is followed by five physical activity blocks which viewers can actively take part in at home: (1) warmingup; (2) arms-legs coordination; (3) cardiofitness; (4) muscular strength; (5) cooling-down. Two instructors take turns leading the exercises of an exercise group of five persons in the studio. The members of this exercise group, participating in the exercises in the background, are carefully selected. Both obese and nonobese, males and females, young and old participants, native as well as people from other ethnic origins are performing the exercises in the background, as a result of which all viewers can identify themselves with these role models. The program ends with a short feature highlighting various physical activities and sports. A popular activity such as line dancing may be introduced, or information is provided about being active when suffering from diseases such as cancer or osteoarthritis, or an upcoming sports event may be announced. NOM-tv is supported by a Web page, and DVDs have been released.

Hopman-Rock et al. [15] identified determinants of participation in NOM-tv in a cohort study among an age stratified quota sample (random digit dialing throughout the Netherlands) of people aged 35-55 years and 55 years and over. The study gave insight into the characteristics of viewers and nonviewers. The researchers found that NOMtv particularly appealed to older women who perceive few barriers to participation and have a reasonable knowledge about the benefits of physical activity. Furthermore, the program also seemed particularly appealing to people at the lower stage of change levels. Hopman-Rock et al. [15] therefore concluded that NOM-tv contributes to compliance with the physical activity guidelines by people who are generally difficult to reach.

Mass media campaigns can be seen as a means to raise awareness about physical activity and health in the general population [16]. Although several mass media campaigns have effectively promoted physical activity by educational messages through various mass media channels $[16,17]$, no previous research has been conducted into the factors that explain participation in physical activity programs on television.

According to the Self-Determination Theory [18], participation in physical activities can lead to feelings of enjoyment, personal challenge, and a sense of competence about being physically active. These motives to engage in exercise are likely to be perceived as autonomous and reflect intrinsic motivation to exercise. For people having such intrinsic orientations towards exercise, participation is likely to be accompanied by a sense of volition and freedom from pressure. Furthermore, engaging in exercise will be accompanied by positive exercise-related cognitions and affect, and long-term commitment can be expected. On the other hand, some people tell themselves, for instance, that they "must exercise to lose weight". Types of exercise motivation such as improving appearance or pleasing others are more likely to be perceived as internally controlling, which reflects extrinsic motivation. When someone has internally controlling motives, exercising will be accompa- nied by feelings of tension and pressure to act. As a result, long-term commitment is less likely $[19,20]$. Empirical research supports these tenets of the Self-Determination Theory in an exercise context: greater enjoyment, higher perceived competence, and autonomous exercise motivation are significantly associated with higher physical activity levels [21-27]. Even with regard to exercise adherence over time, empirical evidence shows a positive association between autonomous motivation and sustained exercise participation [25-27].

The development of NOM-tv was based on the Social Cognitive Theory [28]. Observational learning, the process of learning which occurs when a person watches the actions of another person and the reinforcements that the person receives, is a central idea of the Social Cognitive Theory. Observational learning is part of social modeling, which is one of the four means to increase self-efficacy [29]. In NOMtv, social modeling is operationalized by the instructors who function as role models and give instruction and guidance on how to perform the NOM-tv exercises. Besides, the program involves a wide variety of people exercising in the background, who can as well be viewed as important role models. Viewers are likely able to identify with some of the background exercisers. Observational learning asserts that viewers can witness observed behaviors of the background participants and then reproduce the same actions. As a result of this, behavioral capability and self-efficacy are enhanced. In the development of NOM-tv the difficulty level of the exercises has also been taken into account and during a pilot of the program the difficulty level of the exercises was adjusted to the target population. The exercises should be executable in the living room and be both performable for healthy people, as well as for viewers with minor health problems such as reduced mobility or asthma. These people are advised to use a chair for the exercises which is also demonstrated by some background participants.

The main goal of the present study was to explore which underlying motivations were associated with participating in the NOM-tv exercises. Since providing role models and enhancing self-efficacy and behavioral capability are central goals of NOM-tv, it can be expected that participation in the NOM-tv exercises can lead to an increased sense of competence about being physically active. Therefore, we hypothesized a positive relationship between perceived competence and participation in NOM-tv. We assessed motivational regulation by means of the intrinsic motivation inventory (IMI; $[26,30]$ ), an instrument based on the SelfDetermination Theory. The IMI determines respondents' levels of intrinsic motivation as an additive function of six underlying dimensions (interest-enjoyment, perceived competence, effort-importance, pressure-tension, perceived choice, and value-usefulness). The instrument has gained widespread acceptance as a multidimensional measure of intrinsic motivation in the context of sports and physical activity [26, 30-33]. Based on the Self-Determination Theory, our second hypothesis was that respondents, who perceived more autonomous motives to engage in the NOMtv exercises, would also participate more often in the NOMtv exercises. 


\section{Method}

2.1. Design of the Study. A cross-sectional study was carried out among viewers of NOM-tv. In accordance with Dutch ethical guidelines, approval by an ethics committee was not requested for this survey study. Participants were informed that all provided information would be treated confidentially and would only be used anonymously for research purposes. Respondents were recruited through the Web page of the Dutch public channel which broadcasts NOM-tv (MAX), and through several other Web pages of partner organizations that help coordinate NOM-tv (including the Netherlands Institute for Sport and Physical Activity and the Dutch Heart Foundation). The recruitment took place from May 18 until June 30, 2009. During this period, 1,737 viewers of NOM-tv completed the questionnaire. Viewers who participated in the NOM-tv exercises and had less than eight missing values on the IMI were included in this study. This brought the total number of respondents in this study to 1,349 people $(77.7 \%)$. Missing values were replaced by the item mean scores.

\subsection{Measures}

2.2.1. Basic Characteristics. The questionnaire addressed the following background variables: gender, age, marital status, current occupational status, and nationality. Body mass index (BMI) in kilograms per square meter was calculated from self-reported weight $(\mathrm{kg})$ and height $(\mathrm{m})$. Respondents were asked to report their educational level, which was categorized into low (no education, primary, or lower vocational school) and high (secondary vocational school, high school, higher professional education, or university). The level of urbanization was defined by whether respondents reported to live in a town or city, or in a village. Perceived personal health status was measured by asking respondents to rate their perceived health on a scale from 1 to 10 (with 10 representing the most positive score).

Respondents were also asked to report how many minutes a day they had spent performing mildly intensive, moderately intensive, and highly intensive physical activities on average during the past week, based on the validated Short Questionnaire to Assess Health Enhancing Physical Activity (SQUASH) [34]. For example with regard to the question how much time a day people spent on average in the past week on moderately intensive physical activities (like dancing, working in the garden, etc.), respondents could answer 0 minutes a day (1), less than 30 minutes a day (2), 30-60 minutes a day (3), 1-2 hours a day (4), or more than 2 hours a day (5). The scores on the variables measuring moderately intensive and highly intensive physical activities were summed to determine whether people were at least moderately physically active for a minimum of 30 minutes a day. Respondents who answered option 3 (or higher) on one or both variables were classified as meeting the Dutch physical activity guidelines, which state that every adult should accumulate 30 minutes or more of moderately intense physical activity on at least five, preferably all, days of the week [35].
Viewing habits were measured by asking how many times a week respondents watched NOM-tv. The answering categories were "less than weekly (1)", "1-2 times a week (2)", "3-4 times a week (3)," and "5-7 times a week (4)".

2.2.2. Intrinsic Motivation Inventory. The Intrinsic Motivation Inventory was used to measure respondents' subjective experience with regard to participation in the NOM-tv exercises, measured in six dimensions. The interest-enjoyment subscale is considered to be the self-report measure of intrinsic motivation (7 items, e.g., "I enjoy participating in the NOM-tv exercises very much"). Perceived competence to perform the NOM-tv exercises can be seen as a positive predictor of both self-report and behavioral measures of intrinsic motivation ( 5 items, e.g., "I am pretty skilled at participating in the NOM-tv exercises"). The effort-importance subscale determined whether respondents thought NOM-tv was important to them and whether they were willing to put effort into participating in the NOM-tv exercises (5 items, e.g., "I put a lot of effort into participating in the NOM-tv exercises"). The pressure-tension subscale is assumed to be a negative predictor of intrinsic motivation ( 5 items, e.g., "I felt very tense while participating in the NOM-tv exercises"). Perceived choice in performing the NOM-tv exercises is considered a positive predictor of intrinsic motivation (7 items, e.g., "I participated in the NOM-tv exercises because I wanted to"). Finally, the value-usefulness subscale can also be viewed as a positive predictor of intrinsic motivation, since people internalize and become self-regulating with respect to activities that they perceive as useful or valuable for themselves ( 7 items, e.g., "I believe that participating in the NOM-tv exercises could be beneficial to me"). All items were rated on a 7 -point Likert scale, ranging from 1 (not at all true) to 7 (very true). The pressure-tension subscale was reversed, as high pressure-tension is negatively associated with intrinsic motivation. Negatively formulated items in other subscales were also reversed. Subscale scores were then calculated by averaging across all items within one subscale. Higher scores indicated a more internal, self-regulated type of behavior.

2.2.3. Participation in the NOM-tv Exercises. The outcome measure in the present study, participation in the NOM-tv exercises, was measured by asking how often respondents actively participated in the NOM-tv exercises: "occasionally (0)" or "every time/nearly every time (1)".

2.3. Data Analysis. Analyses were carried out using SPSS 15.0 software (SPSS inc., Chicago, ILL, USA) in four steps. First, reliability analyses were carried out for all IMI subscales. Internal consistency of the six IMI subscales was generally satisfactory [24], with the following Cronbach's alphas: interest-enjoyment $(\alpha=.78 ; \mathrm{M}=6.06 ; \mathrm{SD}=1.36)$, perceived competence $(\alpha=.82 ; \mathrm{M}=5.14 ; \mathrm{SD}=1.52)$, effortimportance $(\alpha=.75 ; \mathrm{M}=6.26 ; \mathrm{SD}=1.26)$, pressure-tension $(\alpha=.64 ; \mathrm{M}=1.59 ; \mathrm{SD}=1.34)$, perceived choice $(\alpha=.67$; $\mathrm{M}=6.65 ; \mathrm{SD}=1.03)$, and value-usefulness $(\alpha=.84 ; \mathrm{M}$ $=6.14 ; \mathrm{SD}=1.11)$. The IMI subscales were then correlated with exercise behavior and viewing habits. The third step 
TABLE 1: Background characteristics of the respondents $(N=1,349)$.

\begin{tabular}{|c|c|c|c|}
\hline \multirow{2}{*}{ Gender } & Male & & $16.1 \%$ \\
\hline & Female & & $83.9 \%$ \\
\hline \multirow{5}{*}{ Age } & $<55$ & & $11.4 \%$ \\
\hline & $55-65$ & & $39.1 \%$ \\
\hline & $65-75$ & & $35.6 \%$ \\
\hline & $>75$ & & $13.9 \%$ \\
\hline & & mean $(\mathrm{SD})$ & $64.7(8.7)$ \\
\hline \multirow{5}{*}{ BMI } & $<18,5$ (underweight) & & $0.7 \%$ \\
\hline & 18,5-25 (normal/healthy weight) & & $44.3 \%$ \\
\hline & 25-30 (overweight) & & $39.9 \%$ \\
\hline & $>30$ (obese) & & $15.0 \%$ \\
\hline & & mean $(\mathrm{SD})$ & $26.1(4.2)$ \\
\hline \multirow{4}{*}{ Marital status } & Married or living together with partner & & $62.3 \%$ \\
\hline & Unmarried and never been married & & $5.4 \%$ \\
\hline & Divorced/living separately & & $15.8 \%$ \\
\hline & Widow/widower & & $16.5 \%$ \\
\hline \multirow{4}{*}{ Current occupational status } & Working & & $19.5 \%$ \\
\hline & Housewife/-man & & $17.5 \%$ \\
\hline & Retired/early retirement & & $51.0 \%$ \\
\hline & Not occupied/other options & & $12.1 \%$ \\
\hline \multirow{2}{*}{ Educational level } & Low & & $44.5 \%$ \\
\hline & High & & $55.5 \%$ \\
\hline \multirow{2}{*}{ Urbanization } & Village & & $47.4 \%$ \\
\hline & Town or city & & $52.6 \%$ \\
\hline \multirow{2}{*}{ Nationality } & Dutch & & $94.8 \%$ \\
\hline & Other nationality & & $5.2 \%$ \\
\hline Perceived personal health status & Rating on scale of $1-10$ & mean $(\mathrm{SD})$ & $7.3(1.2)$ \\
\hline \multirow{2}{*}{ Compliance with physical activity guidelines (SQUASH) } & Not complying with guidelines & & $52.3 \%$ \\
\hline & Complying with guidelines & & $47.7 \%$ \\
\hline \multirow{4}{*}{ Viewing habits } & Watching less than weekly & & $6.1 \%$ \\
\hline & Watching 1-2 times a week & & $20.3 \%$ \\
\hline & Watching 3-4 times a week & & $41.0 \%$ \\
\hline & Watching 5-7 times a week & & $32.5 \%$ \\
\hline \multirow{2}{*}{ Participation in the NOM-tv exercises } & Participating occasionally & & $22.4 \%$ \\
\hline & Participating every time/nearly every time & & $77.6 \%$ \\
\hline
\end{tabular}

was an independent samples $t$-test to investigate whether the respondents who reported a low frequency of participation in the NOM-tv exercises had different scores on the six IMI subscales, compliance with the physical activity guidelines, and viewing habits than those who reported a higher frequency of participation in the NOM-tv exercises. Finally, a logistic regression analysis was used to explain participation in the NOM-tv exercises, with the IMI subscales as independent variables, corrected for demographic variables, perceived personal health status, compliance with the physical activity guidelines, and viewing habits.

\section{Results}

An overview of the respondents' background characteristics is given in Table 1. Women were clearly overrepresented in the viewer population (83.9\%). Most of the respondents were between 55 and 75 years old, with a mean age of 64.7 years. More than half of all respondents were overweight/obese. Most people were married or living with a partner, and more than half of all respondents were retired. Slightly more than half of the respondents were highly educated and lived in a town or city. Almost all respondents had Dutch nationality. Respondents were moderately positive about their personal health status, with an average rating of 7.3 (SD 1.2). Furthermore, $47.7 \%$ of the respondents complied with the Dutch physical activity guidelines.

Regarding viewing habits, most respondents (41.0\%) indicated that they watched NOM-tv 3 or 4 times a week, whereas $32.5 \%$ reported watching it 5-7 times a week. One out of four respondents viewed NOM-tv twice a week or less. Approximately three out of four respondents reported participating in NOM-tv every time or nearly every time. 
TABLE 2: Correlation matrix for the six IMI subscales, compliance with the physical activity guidelines, and viewing habits.

\begin{tabular}{|c|c|c|c|c|c|c|c|}
\hline & $\mathrm{I} / \mathrm{E}^{*}$ & $\mathrm{PCo}^{*}$ & $\mathrm{E} / \mathrm{I}^{*}$ & $\mathrm{P} / \mathrm{T}^{*}$ & $\mathrm{PCh}^{*}$ & $\mathrm{~V} / \mathrm{U}^{*}$ & Compliance PA guidelines \\
\hline $\mathrm{I} / \mathrm{E}^{*}$ & - & & & & & & \\
\hline PCo* & .462 & - & & & & & \\
\hline $\mathrm{E} / \mathrm{I}^{*}$ & .487 & .501 & - & & & & \\
\hline $\mathrm{P} / \mathrm{T}^{*}$ & -.324 & -.434 & -.432 & - & & & \\
\hline $\mathrm{PCh}^{*}$ & .197 & .222 & .334 & -.417 & - & & \\
\hline $\mathrm{V} / \mathrm{U}^{*}$ & .496 & .312 & .430 & -.314 & .224 & - & \\
\hline Compliance PA guidelines* & $.059^{\mathrm{b}}$ & .178 & $.064^{\mathrm{b}}$ & -.116 & .076 & $-.018^{\mathrm{a}}$ & - \\
\hline Viewing habits & .311 & .322 & .282 & -.184 & $.009^{\mathrm{a}}$ & .268 & $-.037^{\mathrm{a}}$ \\
\hline
\end{tabular}

Note. ${ }^{*} \mathrm{I} / \mathrm{E}=$ interest-enjoyment subscale; $\mathrm{PCo}=$ perceived competence subscale; $\mathrm{E} / \mathrm{I}=$ effort-importance subscale; $\mathrm{P} / \mathrm{T}=$ pressure-tension subscale; $\mathrm{PCh}=$ perceived choice subscale; $\mathrm{V} / \mathrm{U}=$ value-usefulness subscale; compliance $\mathrm{PA}$ guidelines = compliance with physical activity guidelines .

Correlations were significant at a level of $P<.01$ (2-tailed), except for:

(a) not significant,

(b) significant at a level of $P<.05$.

TABLE 3: T-test between the six IMI subscales, compliance with the physical activity guidelines, viewing habits and participation in the NOM-tv exercises.

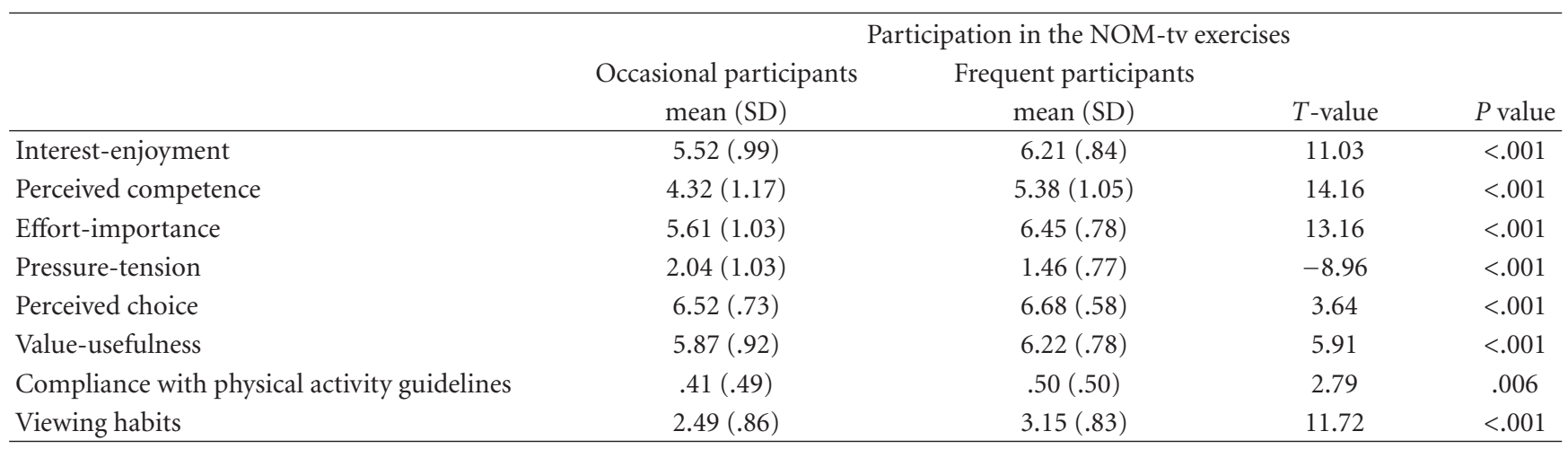

Note. Compliance with physical activity guidelines was measured by: non-compliance (0) versus compliance (1); Viewing habits were measured by: watching less than weekly (1), watching 1-2 times a week (2), watching 3-4 times a week (3) and watching 5-7 times a week (4).

Table 2 presents the correlations between the IMI subscales, compliance with the physical activity guidelines, and viewing habits. The correlation coefficients show that there were strong associations between the IMI subscales, in the expected direction. Moreover, there were strong positive correlations between viewing habits and interest-enjoyment, perceived competence, effort-importance and value-usefulness, whereas a negative association was observed between pressure-tension and viewing habits. These correlations indicate that the more intrinsically motivated people are to participate in the NOM-tv exercises, the more likely they are to watch the program.

Occasional participants differed from frequent participants (Table 3), in that frequent participants enjoyed participating more, experienced higher levels of perceived competence and perceived choice, valued the exercises more, and put more effort into the exercises. Those who perceived less tension or pressure more often engaged in the exercises as well. Finally, frequent participants were more active in their daily lives and more frequently watched the program.

Table 4 shows the results of the logistic regression analysis used to determine the predictive value of the IMI subscales for participation in the NOM-tv exercises, corrected for demographic variables, perceived personal health status, compliance with the physical activity guidelines and viewing habits. Model 1 shows that being female, having a lower BMI, having a higher educational level, complying with the physical activity guidelines and more frequent viewing habits were significantly associated with a higher frequency of participation in the NOM-tv exercises. Model 2-adding the IMI subscales to the background characteristics-shows that the IMI subscales of enjoying the exercises more, having a higher level of perceived competence to perform the exercises, being willing to put more effort into the exercises, and attaching less value to NOM-tv were significantly associated with a higher frequency of participation in the NOM-tv exercises. Gender and compliance with the physical activity guidelines did not add significantly to the model that included the IMI subscales, whereas living in a village did not significantly add to Model 1, but did appear as a significant factor in Model 2. A total of 35\% of the variance in NOM-tv exercise participation was explained.

\section{Discussion}

The present study examined the underlying type of motivation among viewers of NOM-tv for participating in the 
TABLE 4: Logistic regression analysis of the IMI subscales on participation in the NOM-tv exercises, corrected for background characteristics.

\begin{tabular}{|c|c|c|c|c|}
\hline \multirow[t]{2}{*}{ Independent variables } & \multicolumn{2}{|c|}{ Model 1} & \multicolumn{2}{|c|}{ Model 2} \\
\hline & $\mathrm{OR}(\mathrm{CI})$ & $P$ value & $\mathrm{OR}(\mathrm{CI})$ & $P$ value \\
\hline Gender & $1.81(1.18-2.76)$ & .006 & $1.57(.99-2.50)$ & ns \\
\hline Age & $1.00(.98-1.03)$ & ns & $1.02(1.00-1.04)$ & ns \\
\hline BMI & $.91(.88-.95)$ & $<.001$ & $.95(.91-.99)$ & .011 \\
\hline Marital status & $.89(.78-1.03)$ & ns & $.92(.79-1.07)$ & $\mathrm{ns}$ \\
\hline Occupational status & $.98(.88-1.09)$ & ns & $.96(.86-1.07)$ & $\mathrm{ns}$ \\
\hline Educational level & $1.41(1.03-1.94)$ & .034 & $1.62(1.14-2.29)$ & .007 \\
\hline Urbanization & $.79(.58-1.08)$ & $\mathrm{ns}$ & $.71(.50-.99)$ & .044 \\
\hline Nationality & $.71(.37-1.36)$ & ns & $.55(.27-1.09)$ & $\mathrm{ns}$ \\
\hline $\begin{array}{l}\text { Perceived personal } \\
\text { health status }\end{array}$ & $1.12(.99-1.27)$ & ns & $.99(.86-1.14)$ & ns \\
\hline $\begin{array}{l}\text { Compliance with } \\
\text { physical activity } \\
\text { guidelines }\end{array}$ & $1.49(1.09-2.05)$ & .014 & $1.20(.85-1.70)$ & ns \\
\hline Viewing habits & $2.47(2.06-2.95)$ & $<.001$ & $1.86(1.51-2.28)$ & $<.001$ \\
\hline Interest-enjoyment & & & $1.38(1.11-1.70)$ & .003 \\
\hline Perceived competence & & & $1.55(1.29-1.86)$ & $<.001$ \\
\hline Effort-importance & & & $1.65(1.32-2.07)$ & $<.001$ \\
\hline Pressure-tension & & & $.84(.68-1.05)$ & ns \\
\hline Perceived choice & & & $.78(.58-1.06)$ & ns \\
\hline Value-usefulness & & & $.78(.62-.98)$ & .034 \\
\hline Nagelkerke’s $R^{2}$ & \multicolumn{2}{|c|}{.21} & \multicolumn{2}{|c|}{.35} \\
\hline
\end{tabular}

Note. $\mathrm{ns}=$ not significant.

program's exercises, in order to assess whether NOM-tv promotes more autonomous or more controlling participation motives. Useful information can be deduced from this study about people's motives to take part in exercises presented via television, a channel which typically evokes sedentary behavior.

Whereas Martin and Sinden [36] reported a lack of theory-based systematic research examining predictors of exercise adherence, the results of the current theory-based study show that enjoyment, higher perceived competence, and higher willingness to put effort into the NOM-tv exercises - thus showing higher levels of intrinsic motivation-were generally associated with more frequent participation in the exercises. Based on the theoretical ground of NOM-tv, we expected a positive relationship between perceived competence and participation in NOM-tv. Based on the Self-Determination Theory, we expected that respondents who perceived more autonomous motives to engage in the NOM-tv exercises would also participate more often in the NOM-tv exercises. We can conclude that both hypotheses were confirmed.

The present study also revealed the characteristics of frequent participants in the NOM-tv exercises versus occasional participants. The results showed that frequent viewers were also more likely to participate, as were people who were more active in their daily lives. Other subgroups of our study population more likely to participate in the NOM-tv exercises included people with a lower BMI, people living in a village, and people with a higher educational level. Comparing these results to the findings in the study of Hopman-Rock et al. [15], participants in both studies were mainly older women. As NOM-tv was designed for adults (mainly targeting people aged 55 and over), on the one hand it can be concluded that NOM-tv probably reaches its target audience. On the other hand, the present study revealed that more frequent participants were people who were more active in their daily lives, had a lower BMI and a higher educational level, whereas lower educated people with lower activity levels and a higher BMI could be viewed as those who are most in need of a physical activity intervention, and therefore, the program should also aim to get these people started. Due to the cross-sectional design, it can however not be concluded whether this higher activity level of frequent participants was reinforced by participation in the NOMtv exercises or that NOM-tv is particularly appealing for individuals who already tend to be active by themselves. Regardless the result that higher educated, more active respondents with normal weight participated more in the NOM-tv exercises, people who are more in need of reducing sedentary behavior - that is, people with lower educational levels and higher BMI-were also a substantial part of our sample. Therefore, it can be concluded that those people were also attracted to viewing; however, they could use some more (autonomy-supportive) stimulation to also participate in the NOM-tv exercises. 
Given that the independent samples $t$-test showed that frequent participants in the NOM-tv exercises valued the exercises more than occasional participants, it was remarkable that attaching value to NOM-tv seemed to predict less participation in the multivariate analysis. Apparently, the constructs of interest-enjoyment, perceived competence and effort-importance were such influential predictors of participation that the predictive value of the value-usefulness subscale was overridden. The percentage of variance explained by the two logistic regression models was reasonably high, and the internal consistency of the six IMI subscales was generally satisfactory.

The predictive value of the interest-enjoyment, perceived competence, and effort-importance subscales on selfregulation of exercise behavior has also been found in previous studies [26, 37-39]. With regard to participating in a television exercise program, our study confirmed the importance of enjoying physical activity, feeling competent to perform the activity and being willing to put effort into the activity. Since intrinsic motivation is regarded as the most important predictor of sustained physical activity [19], it seems plausible that participation in the exercises will be sustained over time. However, the cross-sectional design of the current study precluded definitive conclusions on this issue. The use of self-report measures was another limitation in this study, which might have led to inaccurate recall and social desirability bias. Sallis and Saelens [40] state that people tend to overestimate their physical activity level in self-report measures, which in the present study might have led to overreporting of respondents' actual physical activity levels. Besides, NOM-tv comprises five physical activity blocks. By the measures used in the present study, it could not be indicated whether or not the respondents engaged in all five blocks each time.

It can be recommended to develop more research studies regarding motivational mechanisms influencing exercise engagement and reducing sedentary behavior in the future. Since Self-Determination Theory-based studies have been predominantly cross-sectional [25], we would advise to include a pre- and postintervention measurement.

With regard to developing future interventions to stimulate people to reduce sedentary behaviors, we would recommend that mass media interventions encourage people's intrinsic orientations towards physical activity in an autonomy-supportive way, in which pressure to engage in the specific physical activity is minimized and people are encouraged to initiate actions based on their personal goals and values [19]. Furthermore, it can be recommended to promote the intrinsic fun and excitement of exercise, which-like in NOM-tv-could be done by selecting enthusiastic instructors and making use of music, either as a beat to follow or just an enjoyable and motivating background $[20,41]$. Besides, it is recommended to support participants' perceived competence in executing the exercises, for example, by encouraging active experimentation, providing good instructions and guidance, and promoting confidence (e.g., through modeling) $[27,41]$.

\section{References}

[1] K. Wijndaele, B. M. Lynch, N. Owen, D. W. Dunstan, S. Sharp, and J. F. Aitken, "Television viewing time and weight gain in colorectal cancer survivors: a prospective population-based study," Cancer Causes \& Control, vol. 20, no. 8, pp. 1355-1362, 2009.

[2] S. Krishnan, L. Rosenberg, and J. R. Palmer, "Physical activity and television watching in relation to risk of type 2 diabetes: the black women's health study," American Journal of Epidemiology, vol. 169, no. 4, pp. 428-434, 2009.

[3] K. Wijndaele, G. N. Healy, D. W. Dunstan et al., "Increased cardiometabolic risk is associated with increased TV viewing time," Medicine and Science in Sports and Exercise, vol. 42, no. 8, pp. 1511-1518, 2010.

[4] R. A. Howard, D. M. Freedman, Y. Park, A. Hollenbeck, A. Schatzkin, and M. F. Leitzmann, "Physical activity, sedentary behavior, and the risk of colon and rectal cancer in the NIHAARP Diet and Health Study," Cancer Causes and Control, vol. 19, no. 9, pp. 939-953, 2008.

[5] M. T. Hamilton, D. G. Hamilton, and T. W. Zderic, "Role of low energy expenditure and sitting in obesity, metabolic syndrome, type 2 diabetes, and cardiovascular disease," Diabetes, vol. 56, no. 11, pp. 2655-2667, 2007.

[6] D. W. Dunstan, E. L. M. Barr, G. N. Healy et al., "Television viewing time and mortality: the australian diabetes, obesity and lifestyle study (ausdiab)," Circulation, vol. 121, no. 3, pp. 384-391, 2010.

[7] M. Inoue, H. Iso, S. Yamamoto et al., "Daily total physical activity level and premature death in men and women: results from a large-scale population-based cohort study in Japan (JPHC study)," Annals of Epidemiology, vol. 18, no. 7, pp. 522$530,2008$.

[8] P. T. Katzmarzyk, T. S. Church, C. L. Craig, and C. Bouchard, "Sitting time and mortality from all causes, cardiovascular disease, and cancer," Medicine and Science in Sports and Exercise, vol. 41, no. 5, pp. 998-1005, 2009.

[9] A. Bauman, T. Armstrong, J. Davies et al., "Trends in physical activity participation and the impact of integrated campaigns among Australian adults, 1997-1999," Australian and New Zealand Journal of Public Health, vol. 27, no. 1, pp. 76-79, 2003.

[10] J. F. Bean, S. G. Leveille, D. K. Kiely, S. Bandinelli, J. M. Guralnik, and L. Ferrucci, "A comparison of leg power and leg strength within the inCHIANTI study: which influences mobility more?" Journals of Gerontology —Series A, vol. 58, no. 8, pp. 728-733, 2003.

[11] L. D. Gillespie, W. J. Gillespie, M. C. Robertson, S. E. Lamb, R. G. Cumming, and B. H. Rowe, "Interventions for preventing falls in elderly people," Cochrane Database of Systematic Reviews (Online), no. 3, article CD000340, 2003.

[12] D. W. Brown, L. S. Balluz, G. W. Heath et al., "Associations between recommended levels of physical activity and healthrelated quality of life: findings from the 2001 Behavioral Risk Factor Surveillance System (BRFSS) survey," Preventive Medicine, vol. 37, no. 5, pp. 520-528, 2003.

[13] M. Leurs, "Programma promoot lichaamsbeweging als onderdeel dagelijks leven," Tijdschrift Voor Gezondheidsvoorlichting, vol. 13, no. 3, pp. 14-15, 1996.

[14] M. P. A. Bouman, J. J. M. Meis, and S. P. J. Kremers, Nederland in Beweging!-tv. Gebruikswaardeonderzoek 2009, Centrum Media \& Gezondheid, Gouda, The Netherlands, 2009.

[15] M. Hopman-Rock, J. A. J. Borghouts, and M. T. W. Leurs, "Determinants of participation in a health education and 
exercise program on television," Preventive Medicine, vol. 41, no. 1, pp. 232-239, 2005.

[16] A. Bauman, B. J. Smith, E. W. Maibach, and B. Reger-Nash, "Evaluation of mass media campaigns for physical activity," Evaluation and Program Planning, vol. 29, no. 3, pp. 312-322, 2006.

[17] B. H. Marcus, N. Owen, L. H. Forsyth, N. A. Cavill, and F. Fridinger, "Physical activity interventions using mass media, print media, and information technology," American Journal of Preventive Medicine, vol. 15, no. 4, pp. 362-378, 1998.

[18] E. L. Deci and R. M. Ryan, Intrinsic Motivation and SelfDetermination in Human Behavior, Plenum, New York, NY, USA, 1985.

[19] M. S. Hagger and N. L. Chatzisarantis, Intrinsic Motivation and Self-Determination in Exercise and Sport, Human Kinetics, Champaigne, Ill, USA, 2007.

[20] J. R. Whitehead, "Physical activity and intrinsic motivation," Research Digest (President's Council on Physical Fitness and Sports), vol. 1, pp. 1-9, 1993.

[21] B. A. Lewis, B. H. Marcus, R. R. Pate, and A. L. Dunn, "Psychosocial mediators of physical activity behavior among adults and children," American Journal of Preventive Medicine, vol. 23, no. 2, pp. 26-35, 2002.

[22] S. Hardy and S. Grogan, "Preventing disability through exercise: investigating older adults' influences and motivations to engage in physical activity," Journal of Health Psychology, vol. 14, no. 7, pp. 1036-1046, 2009.

[23] R. Puente and M. H. Anshel, "Exercisers' perceptions of their fitness instructor's interacting style, perceived competence, and autonomy as a function of self-determined regulation to exercise, enjoyment, affect, and exercise frequency," Scandinavian Journal of Psychology, vol. 51, no. 1, pp. 38-45, 2010.

[24] M. S. Fortier, S. N. Sweet, T. L. O'Sullivan, and G. C. Williams, "A self-determination process model of physical activity adoption in the context of a randomized controlled trial," Psychology of Sport and Exercise, vol. 8, no. 5, pp. 741757, 2007.

[25] M. Hagger and N. Chatzisarantis, "Self-determination theory and the psychology of exercise," International Review of Sport and Exercise Psychology, vol. 1, no. 1, pp. 79-103, 2008.

[26] J. Buckworth, R. E. Lee, G. Regan, L. K. Schneider, and C. C. DiClemente, "Decomposing intrinsic and extrinsic motivation for exercise: application to stages of motivational readiness," Psychology of Sport and Exercise, vol. 8, no. 4, pp. 441-461, 2007.

[27] M. N. Silva, D. Markland, E. V. Carraça et al., "Exercise autonomous motivation predicts 3-yr weight loss in women," Medicine \& Science in Sports \& Exercise, vol. 43, no. 4, pp. 728$737,2010$.

[28] A. Bandura, "Self-efficacy: toward a unifying theory of behavioral change," Psychological Review, vol. 84, no. 2, pp. 191215, 1977.

[29] A. L. McAlister, C. L. Perry, and G. S. Parcel, "How individuals, environments, and health behaviors interact: social cognitive theory," in Health Behavior and Health Education: Theory, Research, and Practice, pp. 169-188, John Wiley \& Sons, San Francisco, Calif, USA, 4th edition, 2008.

[30] E. McAuley, T. Duncan, and V. V. Tammen, "Psychometric properties of the intrinsic motivation inventory in a competitive sport setting: a confirmatory factor analysis," Research Quarterly for Exercise and Sport, vol. 60, no. 1, pp. 48-58, 1989.

[31] E. L. Deci, H. Eghrari, B. C. Patrick, and D. R. Leone, "Facilitating internalization: the self-determination theory perspective," Journal of Personality, vol. 62, no. 1, pp. 119-142, 1994.

[32] D. Markland and L. Hardy, "On the factorial and construct validity of the intrinsic motivation inventory: conceptual and operational concerns," Research Quarterly for Exercise and Sport, vol. 68, no. 1, pp. 20-32, 1997.

[33] M. N. Silva, P. N. Vieira, S. R. Coutinho et al., "Using selfdetermination theory to promote physical activity and weight control: a randomized controlled trial in women," Journal of Behavioral Medicine, vol. 33, no. 2, pp. 110-122, 2010.

[34] W. Wendel-Vos and J. Schuit, "SQUASH: Short Questionnaire to Assess Health Enhancing Physical Activity," Rijksinstituut voor Volksgezondheid en Milieu [Netherlands Institute for Public Health and Environment], Bilthoven, pp. 1-55, 2002.

[35] H. G. C. Kemper, W. T. M. Ooijendijk, and M. Stiggelbout, "Consensus over de Nederlandse Norm voor Gezond Bewegen [Consensus on the Dutch standard for healthy exercise]," Tijdschrift Voor Sociale Gezondheidszorg , vol. 78, pp. 180-183, 2000.

[36] K. A. Martin and A. R. Sinden, "Who will stay and who will go? A review of older adults' adherence to randomized controlled trials of exercise," Journal of Aging and Physical Activity, vol. 9, no. 2, pp. 91-114, 2001.

[37] P. J. Teixeira, M. N. Silva, S. R. Coutinho et al., "Mediators of weight loss and weight loss maintenance in middle-aged women," Obesity, vol. 18, no. 4, pp. 725-735, 2010.

[38] E. J. M. Wouters, A. M. A. Van Nunen, R. Geenen, R. L. Kolotkin, and A. J. J. M. Vingerhoets, "Effects of aquajogging in obese adults: a pilot study," Journal of Obesity, vol. 2010, Article ID 231074, 7 pages, 2010.

[39] M. A. Napolitano and S. Hayes, "Behavioral and psychological factors associated with 12-month weight change in a physical activity trial," Journal of Obesity, vol. 2011, Article ID 515803, 10 pages, 2011.

[40] J. F. Sallis and B. E. Saelens, "Assessment of physical activity by self-report: status, limitations, and future directions," Research Quarterly for Exercise and Sport, vol. 71, no. 2, pp. 1-14, 2000.

[41] J. H. Biddle and N. Mutrie, Psychology of Physical Activity: Determinants, Well-Being and Interventions, Routledge, London, UK, 2nd edition, 2008. 


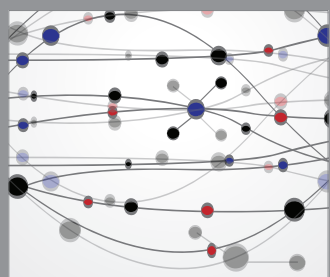

The Scientific World Journal
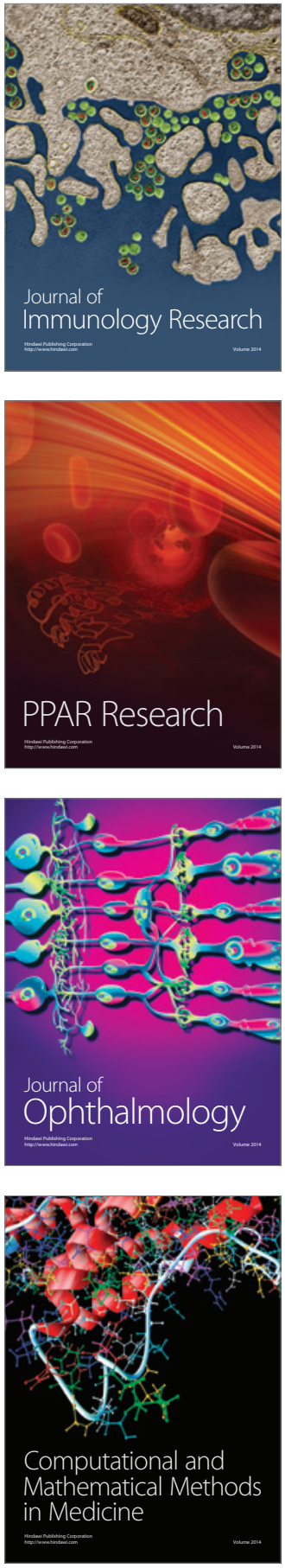

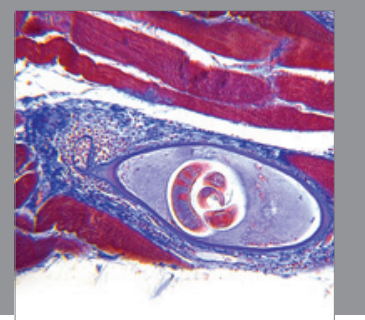

Gastroenterology

Research and Practice
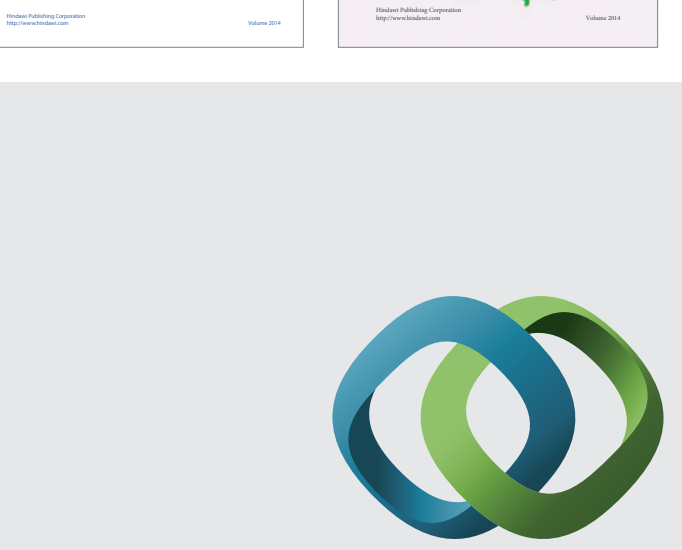

\section{Hindawi}

Submit your manuscripts at

http://www.hindawi.com
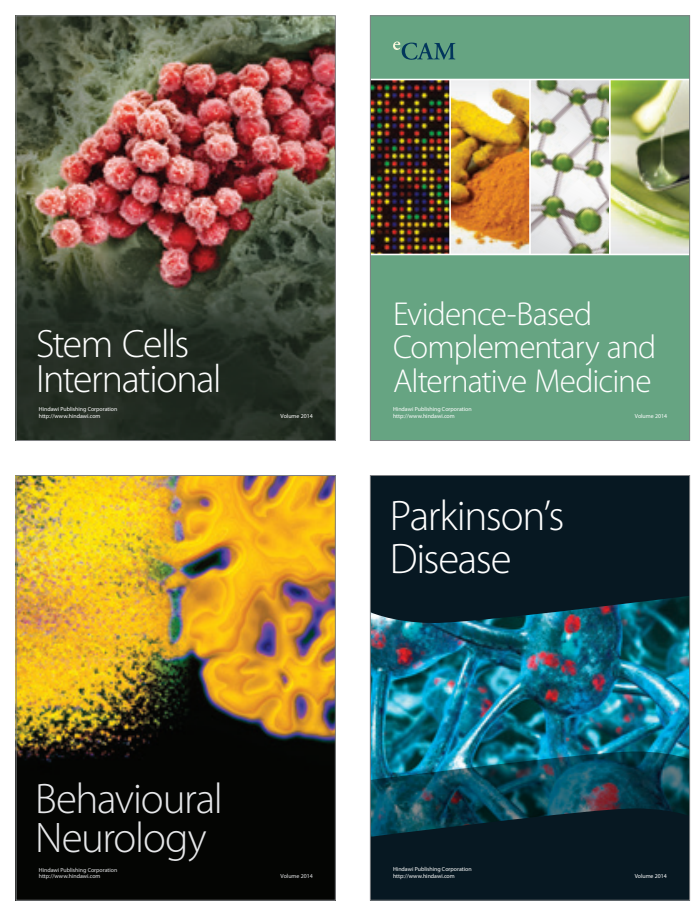

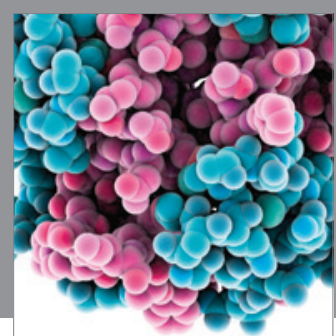

Journal of
Diabetes Research

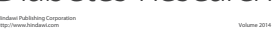

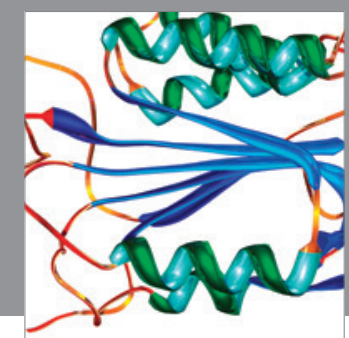

Disease Markers
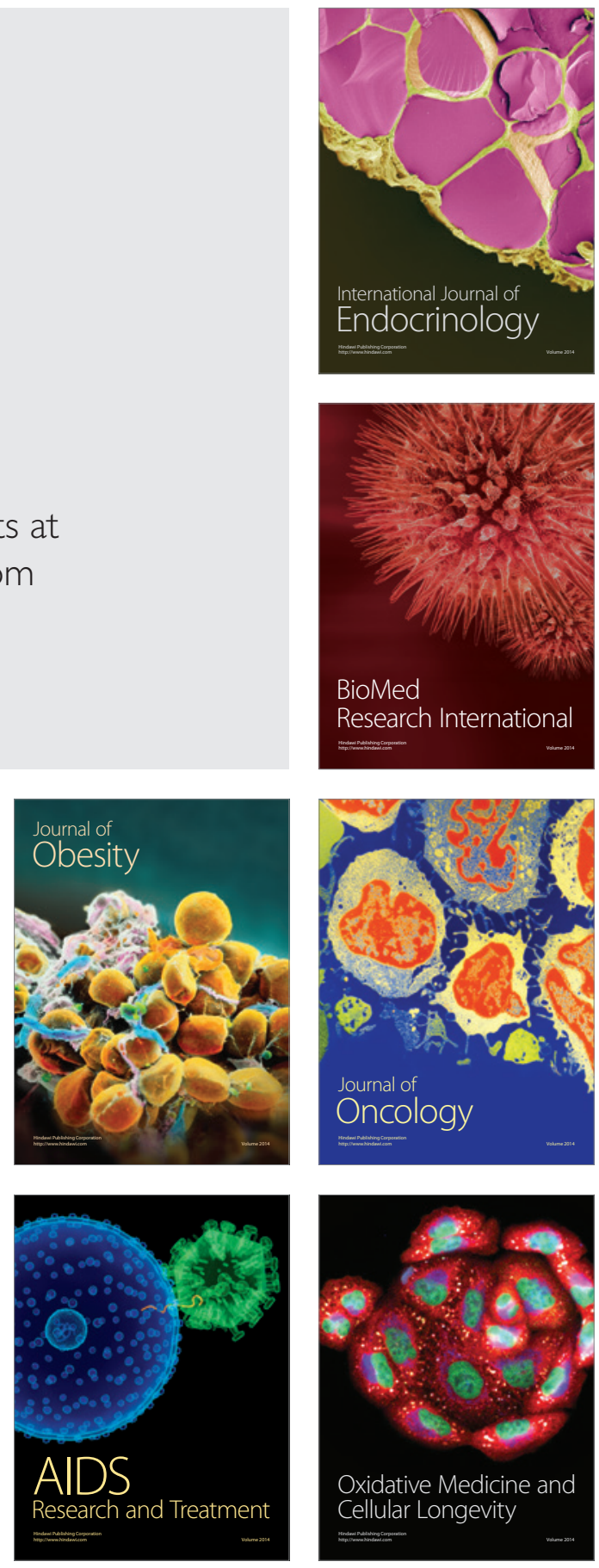